\title{
FINANCIAL INCENTIVES IN DISABILITY INSURANCE IN THE NETHERLANDS
}

\author{
BY
}

\author{
ANNEMIEK H. VAN VUREN* AND DANIEL J. VAN VUUREN**
}

\begin{abstract}
Summary
In this article, we assess the impact of financial incentives on the inflow in the public Disability Insurance (DI) scheme in The Netherlands. For this matter, the variation in replacement rates over different sectors is exploited to estimate the probability of DI enrolment over a sample of employees from the Dutch Income Panel (1996-2000). On the basis of these administrative data, we find a point estimate of the elasticity of DI enrolment with respect to the DI wealth rate of 2.5. Simulations indicate that a 5\%-point rise in replacement rates in the two first years of DI increases DI enrolment by $6 \%$.
\end{abstract}

Key words: disability insurance, financial incentives, moral hazard

\section{INTRODUCTION}

In The Netherlands, as well as in many other western countries, the number of participants in public Disability Insurance (DI) schemes has been growing over the past three decades, which has led to high expenditures on such schemes and a downward pressure on labour force participation. Compared to other countries, the use of DI in The Netherlands is relatively high. In 1999 the number of DI enrolments was 10.4 per 1000 insured workers, whereas enrolment in Germany and US equalled 5.3 and 6.0, respectively. In that same year, public expenditures on DI benefits equalled $2.7 \%$ of GDP in The Netherlands, while for Germany and US expenditures equalled $1.0 \%$ and $0.7 \%$, respectively. ${ }^{1}$ Several possible explanations may exist for this difference. Unlike most other countries, DI in The Netherlands does not distinguish between occupational and social risks, and every worker is fully insured irrespective of his or her work history. Another difference is that disability is insured from a minimum of $15 \%$ of so-called 'earnings capacity', implying that any worker who loses at least $15 \%$ of his/her earnings due to

* CPB Netherlands Bureau for Economic Policy Analysis, P.O. Box 80510, 2508 GM, The Hague, The Netherlands.

** Author for correspondence. Address: CPB Netherlands Bureau for Economic Policy Analysis, P.O. Box 80510, 2508 GM, The Hague, The Netherlands, e-mail: djvv@cpb.nl

1 These figures are drawn from OECD (2003). DI benefits are excluding sickness benefits, work injury benefits, and employment-related programs for the disabled. 
disability will be covered by DI. A fourth reason may be the relatively attractive financial conditions in The Netherlands (OECD (2003)). The influence of these financial conditions on DI enrolment is precisely the topic of this article.

Disability Insurance schemes are meant to provide insurance against the risk of earnings loss due to disability. The growth in DI use can however not be explained by an increase of disability within the population (see, e.g. Aarts and de Jong (1992)). Due to informational problems and imperfect disability evaluation, able people may receive DI benefits instead of working more hours, or receive DI benefits instead of unemployment benefits, early retirement benefits, or welfare. Such improper use may help explaining the expansion of DI use in The Netherlands. Both employers and employees have experienced incentives to make use of DI in an improper way. Employers have often considered DI schemes as a decent way to get rid of workers with lowproductivity compared to their wages, in particular older workers. Moreover, the burden of DI benefits was not directly borne by the employers. ${ }^{2}$ On the other hand, the relatively generous DI benefits have attracted both persons who would otherwise have worked more hours and persons who would have been on early retirement benefits, unemployment benefits, or welfare. In particular, DI is considered to be an important alternative to the 'official' early retirement schemes (Woittiez et al. (1994); Lindeboom (1998); Kerkhofs et al. (1999)). This is further encouraged by the fact that workers experience highimplicit taxes on continued work, as DI benefits are not subject to any actuarial adjustments (Kapteyn and de Vos (1999)).

A number of empirical studies have confirmed the relationship between the number of participants in DI schemes and the local economic situation. Among the first studies for The Netherlands were Van den Bosch and Petersen (1983) and Roodenburg and Wong Meeuw Hing (1985), who both conclude that the stock of DI-beneficiaries in the 1970s contained hidden unemployment. Based on the ratings of insurance physicians and ergonomists, Aarts and de Jong (1992) have estimated the extent to which DI-beneficiaries are able to work, and arrive at an implied structural share of hidden unemployment within the 1980 DI inflow of $33-51 \%$. Estimates of Westerhout (1996) suggest that almost $50 \%$ of all participants in DI schemes in The Netherlands in the period 1973-1992 was in fact hidden unemployment. For later years (1988 and 1990), Hassink et al. (1997) find a hidden unemployment rate in DI inflow of about $10 \% .^{3}$ Moreover, Hassink $(1996,2000)$ finds that about a quarter of the employees enrolling into DI are not replaced by

2 Note that this has changed since 1998, when experience rating was introduced in DI employer premiums. See Koning (2004) for an evaluation of this policy measure.

3 In 1987, a reform of DI took place (this will be discussed in section 2), so that the study of Westerhout (1996) mainly concerns the period before this reform, while the study of Hassink et al. (1997) exclusively deals with years after the reform. 
new workers, that is the concerning jobs are destroyed. For other countries, such as the US, there is an abundance of literature showing that the local DI schemes contain hidden unemployment (see, e.g. Autor and Duggan (2002), Black et al. (2002)).

In an interesting study of Canadian DI, Gruber (2000) makes use of a policy change specific to the Quebec province to estimate the elasticity of labour supply of older persons with respect to DI benefits. His results imply point estimates of the elasticity of labour force non-participation with respect to DI benefits in the range 0.28-0.36. Given the fact that within his dataset the disabled constitute about one fifth of all non-participants, the elasticity of the probability of receiving DI benefits with respect to these benefits would equal about 1.6. This figure is actually even on the conservative side when it is thought that substitution within the category of non-participants is not taken into account, and that Gruber in fact identifies the short term elasticity (Bound and Burkhauser (1999)). For The Netherlands, there is not much empirical evidence on the effect of financial incentives on DI enrolment. Aarts and de Jong (1992) estimate the probability of DI enrolment on a sample of individuals with sickness benefits, and find that a reduction in the replacement rate with $16 \%$ reduces the conditional DI enrolment probability by $54 \%$, which implies a benefit elasticity of 3.5.

This study focuses on the determinants of DI enrolment with a particular focus on the effect of financial incentives. By using a rich micro dataset and sector specific collective labour agreements, we try to identify the elasticity of DI enrolment with respect to DI benefits. As a result of (sector- or firmspecific) collective labour agreements, benefits are usually higher than statutory benefits, and differ for individuals working in different sectors and firms. Therefore, the financial attractiveness of DI schemes differs between different sectors and firms. We exploit this variation in DI benefit levels to identify the effect of financial incentives on DI enrolment. Obviously, a special effort has been made to correct for unobserved sector- and firm-specific effects, so that the estimated elasticity will suffer the least possible from bias due to omitted variables.

This article is organised as follows. Section 2 describes the Dutch DI system, its history and its position among other forms of social security. Section 3 discusses the DI determination process, the determinants of DI enrolment, and the behaviour of individuals and program administrators making the benefit award decisions. In section 4, the data are described, while in section 5 our empirical strategy is discussed. Estimation results are presented in section 6. Finally, concluding remarks and recommendations are given in section 7 . 


\section{INSTITUTIONAL SETTING}

\subsection{A Brief History}

The current Dutch DI system (WAO) was originally introduced in 1967, and was meant to provide insurance against the risk of earnings loss due to disability. During 1970s, the annual growth rate of DI recipients was about $11 \%$, which was much higher than expected at the introduction of the system. Programme expenditures grew even faster, so that corrective policy measures were needed to alleviate the financial burden. During the 1980s various actions were taken, with major adjustments becoming active in 1985 and 1987. Main features of the reforms were the reduction of the replacement rate from 80 to $70 \%$, introduction of a more equal treatment of men and women, and disconnection of the disability and unemployment component in the DI programme by removing labour market considerations from disability assessment. In that same year, Unemployment Insurance (UI) was reformed as well, most notably by the introduction of work experience as a criterion for unemployment benefit duration.

However, in the early 1990s it became clear that these adjustments did not lead to the expected volume and cost reducing effects. Thus, the second phase of reforms started. More financial incentives were introduced to confront both employees and employers with the financial consequences of the excessive use of sickness and disability benefits. In 1992, a premium differentiation system for sickness benefits and a (not long-lived) no-claim bonus system were introduced (TAV). The system implied that employers had to pay a penalty for each one of their employees entering the DI rolls. On the other hand, a firm employing a DI beneficiary for at least one year received a bonus.

Until 1993, a fully disabled beneficiary received a wage-related benefit $(70 \%)$ of unlimited duration. Since 1993, both the duration of the wagerelated benefit and the level of the benefit have depended on the recipient's age and employment history at the moment of DI enrolment. Depending on the age and work history, a fully disabled beneficiary receives a wage-related benefit $(70 \%)$ for at most 6 years. During the subsequent period, a fully disabled beneficiary has received a base amount of $70 \%$ of the minimum wage plus a supplement depending on age. Partially disabled receive pro rata benefits. However, the difference between the new and old replacement rates has been repaired in practice for about $80 \%$ of the employees through collective labour agreements made by the social partners (Social and Economic Council of The Netherlands (2002)). This will be further discussed in section 4.1.

A restricted own risk for employers for sickness benefits was introduced in 1994 (TZ) in order to reduce absence through illness. Large firms became responsible for the continued payment of wages during the first six weeks 
of sickness, and small firms for the first two weeks. Since 1996 employers must pay sickness benefits during the entire first year (WULBZ). The noclaim bonus system introduced in 1992 was lifted again in 1995 and replaced by a system of experience rating (PEMBA) in 1998. Furthermore firms could decide to opt out of the public system to bear the risk themselves or to reinsure the risk with private insurance companies.

More recent policies during the late 1990s and early 2000s are aimed at achieving a more efficient administration. This has resulted in the merger of five different administrative offices into one public monopoly which is responsible for the administration of all DI and UI benefits in The Netherlands. This is not to say, however, that no further reforms will be made. Based on proposals of the Social and Economic Council of The Netherlands (2002), it is likely that the DI system will be split into two parts: a public insurance for the fully and long-lasting disabled and a private insurance for the temporarily disabled and partially disabled.

\subsection{The Current Position of Disability Insurance in The Netherlands}

Social security in The Netherlands can be divided into employee insurance and national insurance. The first covers risks related to labour market status, such as unemployment, sickness and disability, and is mostly earnings-related. The insured population consists of those who are employed. The second kind of insurance is meant to provide a minimum income guarantee for all inhabitants of The Netherlands. The most obvious examples of national insurance are welfare and old age state pension. ${ }^{4}$ Further examples are disability insurance for non-working younger persons (WAJONG), health care insurance (AWBZ), family allowances (AKW) and surviving relatives' pension (ANW). All national insurance programmes are financed on a pay-as-you-go basis.

Sickness benefits are paid to employees who are unable to work due to sickness. In principle, the gross replacement rate equals $70 \%$ of the previously earned (gross) wage, but as a result of collective labour agreements these sickness benefits are often supplemented up to a replacement rate of $100 \%$. Sickness benefits may last for a maximum of 12 months. ${ }^{5}$ At the end of this period, one may apply for disability benefits. Disability benefits can be granted to persons who would face a loss in income of more than $15 \%$ as a result of disability. ${ }^{6}$ This (estimated) loss in income is often called the degree of disability, and determines the exact amount of DI benefits that will

4 Note that apart from the old age state pension (AOW), most persons older than 65 years are entitled to occupational pensions, which are mostly earnings-related.

5 Since 2004, the period with sickness benefits has been extended to 24 months.

6 Note the contrast with many other countries (e.g. Germany, Sweden, UK), where the loss in work capacity is decisive for receiving DI benefits, not the loss in income. 
be received. Both the cause of disability and the employment history are not relevant for the acceptance decision.

Obviously, DI applicants are for a large part individuals who have simply become incapable to work. The reason for this incapability is irrelevant, i.e. no distinction has been made between 'professional risk' and 'social risk'. The decision to apply for DI benefits might however also be related to economic incentives, and hence act as a substitute for UI, early retirement benefits, and welfare. The frequency of DI enrolment depends on DI programme characteristics, labour market factors and alternative social security program opportunities. Several studies have shown that arrangements such as early retirement, DI, and UI act as a system of substitute pathways. Restricting one of the social security arrangements will therefore affect the use of the other arrangements.

Limiting the conditions for early retirement, for example, may hardly reduce the withdrawal of elderly of the labour market, as they will start using alternative exit routes instead (viz. DI and UI). DI benefits are often perceived to be more attractive than UI benefits. First, DI does not impose a job search requirement. Moreover, UI benefits are of limited duration, while the only temporal aspect of DI entitlement is a periodical re-examination. Improper use of DI benefits as a more generous, and less stigmatising, ${ }^{8}$ alternative to unemployment benefits was quite common in late 1970s and 1980s. It provided employers with a flexible instrument to reduce the labour force at will and kept official unemployment rates low (Aarts and de Jong (1992)). Several studies for The Netherlands have shown that the share of hidden unemployment within DI schemes lies between 10 and $50 \% .^{9}$ Research for the United States shows similar results. Accounting for the role of disability in inducing labour force exit among the low-skilled unemployed, Autor and Duggan (2002) estimated that US unemployment rate would be two-thirds of a percentage point higher were it not for the liberalised DI system.

\section{DISABILITY INSURANCE BENEFITS AND INDIVIDUAL BEHAVIOUR}

Three months before finishing the period on sickness benefits, an individual may apply for DI benefits. Subsequently, the Dutch Social Benefits Administration $\left(\mathrm{UWV}^{10}\right)$ decides on the application. A medical examiner verifies and evaluates (physical) limitations and job opportunities, and, based on this examination, the DI administrator decides whether or not to accept the

7 Note that this is not in accordance with DI in most other western countries, who do make a distinction between both types of risk.

8 Woittiez et al. (1994) show that, holding other factors constant, early retirement benefits and DI benefits are the preferred exit routes from the labour market, while UI benefits are subject to a certain 'stigma effect'.

9 See the references cited in section 1.

10 There used to exist five different administration offices, which merged into UWV in 2000. 


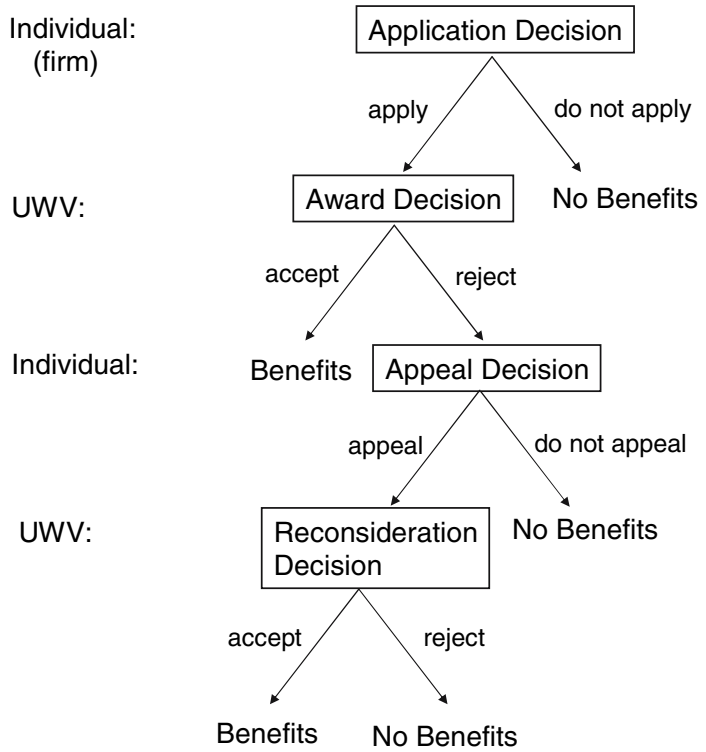

Figure $1-$ Game tree for disability application and award process ${ }^{\mathrm{a}}$

a 'Benefits' may either be 'full benefits' or 'partial benefits' (the latter in case of partial disability)

applicant. In case of acceptance, a benefit is awarded for a period of 5 years, after which a periodical re-examination takes place. The degree of disability is determined by an expert, who compares the applicant's current earnings capacity with his past earnings capacity. A rejected applicant has the opportunity to appeal. The letter of objection must be sent within the period mentioned in the rejection letter. Subsequently, the DI administrator reconsiders the first decision. The application - award - appeal decision is illustrated in Figure 1. Note that if an applicant is denied benefits at the reconsideration stage, then he may exercise the option to have his case considered by court. This is not shown in Figure 1.

Disability Insurance, as well as other employee insurances, suffer from the problem of moral hazard (see, e.g. Barr (1993)). Imperfect information of the DI administrator in the award and reconsideration decisions leads to higher DI enrolment as a result of an adjustment in the behaviour of the insured population. A second form of moral hazard may be a lack in prevention efforts. In this respect, the DI application and appeal decisions of an individual can be regarded as choices between consumption and leisure, given institutions, health conditions, personal characteristics, working conditions and the expected probability of being granted DI benefits. ${ }^{11}$ Obviously, for many 
applicants this labour supply decision will be severely constrained by their health status. These individuals will show high demand for leisure irrespective of the financial conditions involved. Nonetheless, the moral hazard problem just described, together with existing empirical evidence (mainly for countries outside The Netherlands), suggests that factors other than health play a significant role in the behaviour of individuals, in particular financial incentives (see section 1). Thus, individuals who are less constrained by their health status are likely to be sensitive to financial incentives, and raise their demand for leisure as it becomes cheaper (that is: as the DI replacement rate becomes higher).

\section{DATA}

\subsection{Replacement rates}

As was already mentioned in section 2, the exact DI benefit conditions are the result of negotiations by employers' organisations and trade unions. These negotiations, which mostly take place at the sector or firm level, are laid down in collective labour agreements. In the period that will be under consideration, the negotiated collective labour agreements at the sector level were made compulsory by the government for all firms in that sector. The resulting variation in replacement rates over different sectors and firms is exactly the variation we will exploit to identify the elasticity of DI enrolment with respect to the financial incentives involved. The pitfalls involved in this approach will be discussed in later sections.

A database with information on replacement rates for different sectors is available through The Netherlands' Labour Inspectorate. We have made a selection of sectors, such that we were able to match their codes with the sector codes in our dataset of individuals. This is necessary in order to be able to connect both datasets and perform an analysis at the micro level (this will be further discussed in the next subsection). The resulting selection of 39 sectors, with corresponding replacement rates in the year 2002, is given in Appendix A (Table 6). The reported financial indicators are the replacement rate for year $t$ (denoted by $\mathrm{RR}_{t}$ ), and the DI wealth rate (DIWR). This latter variable is defined as the ratio of the sum of all discounted future DI benefits to current income. This definition allows us to conveniently rewrite this indicator in terms of replacement rates $R_{1}, R_{2}$ and $R_{3}$ :

$$
\begin{aligned}
\mathrm{DIWR} & =\frac{1}{y_{0}} \sum_{t=1}^{65-\mathrm{AGE}}\left(\mathrm{RR}_{t} y_{0}\right) \rho^{t-1}=\sum_{t=1}^{65-\mathrm{AGE}} \mathrm{RR}_{t} \rho^{t-1} \\
& =\mathrm{RR}_{1}+\rho \mathrm{RR}_{2}+\frac{\rho^{2}-\rho^{65-\mathrm{AGE}}}{1-\rho} \mathrm{RR}_{3},
\end{aligned}
$$


where $y_{0}$ denotes current income, $\rho$ is a discount factor and $\mathrm{RR}_{3}$ is the replacement rate in the third year and years ahead (i.e. the replacement rate remains constant from the third year on). The mandatory retirement age of 65 is the natural maximum in this expression, as DI benefits automatically stop at this age. The discount factor $\rho$ not only contains the individual's time preference but also represents future uncertainty about receiving DI benefits. For instance, DI recipients who become subject to a medical reassessment may lose their DI benefits. Second, the introduction of new policy measures may affect existing DI recipients.

It can be read from Table 6 that the average replacement rate in the first year equals $89 \%$ of the last earned wage, while the second and third year show average replacement rates of 75 and $70 \%$, respectively. ${ }^{12}$ Thus, the additional benefits on top of the 'official replacement rate' of $70 \%$ are especially high in the first year of Disability Insurance. As was noted in section 2.1, the 1993 reform implied that the earnings related benefits became of limited duration, but that this loss in benefits was 'repaired' in most cases. In Table 6 it becomes clear that nearly all sectors supplement DI benefits from the third year on to $70 \%$ of the last earned wage. Two sectors even have a higher replacement rate for these years of, respectively, 75\% (joinery works) and 80\% (road transport). Most of the variation in replacement rates over different sectors is however in the first and second year. The range of replacement rates in both years is from 70 to $100 \%$. At the average age in our sample (37 years) and a discount rate of $10 \%$, the average 'DI wealth' is seen to equal 6.9 year salaries, with a minimum of 6.6 year salaries (Six different sectors) and a maximum of 7.6 year salaries (road transport).

\subsection{Micro Data}

The Dutch Income Panel dataset "IPO" is based on administrative data from Dutch National Tax Office and was initiated in $1984 .{ }^{13}$ Since 1989 , the dataset consists of a panel of about 75,000 individuals, who are randomly drawn from the Dutch population provided that they were 15 years or older and enlisted in the Dutch municipal registers. Attrition occurs only as a result of emigration or death. In that case new individuals are added to the sample to keep the total number of individuals at the same level. For each individual drawn into the sample several variables are available, which can be divided into three groups:

12 On the basis of our dataset with individual records (see next subsection), the average replacement rates equal 86, 75, and 71 for the first, second, and third year, respectively. 13 The acronym IPO stands for "Income Panel Study" (in Dutch: Inkomens Panel Onderzoek). 
- Variables concerning individual characteristics, such as gender, date of birth, and a variable indicating the sector in which the individual was working;

- Variables concerning household characteristics, such as the number of persons in the household, the number of minor children (age categories) and marital status;

- Financial variables, such as the level of the income, and the source of the income (e.g. wage income, pension benefit, DI benefit, UI benefit). The observation of these variables is in principle on a yearly basis, and relates both to household and individual income. Also, some other financial variables are available, such as outstanding mortgage and real estate appraisal (the so-called "WOZ-value").

The IPO dataset not only contains information on the individuals selected into the sample, but also on the other persons in the households they belong to. These last individuals will also be included in our sample. A great advantage of this administrative dataset is that the observed variables are measured with high accuracy. A drawback of the IPO dataset is however that it lacks some crucial variables which are not related to the household and financial situation of individuals, most notably education and health status. A second drawback is that we are not able to distinguish whether an individual is partially or fully disabled; we can only observe whether an individual receives DI benefits.

For our empirical analysis we use data from the period 1996-2000. We select those individuals into our sample who are eligible for receiving DI benefits in case of disability. That is, all individuals with positive wage income on December 31 of the years 1995-1999 are selected into our sample. These are precisely the individuals who might enter DI in the subsequent years. Thus, according to our definition, an individual enters the DI scheme when he receives wage income at the beginning of the year (formally, on the last day of the previous year) and receives a DI benefit at some other moment of the year. Note that, as a result of this selection process, the self-employed are also removed from our sample. This is correct, as the self-employed have their own DI, which is different from the DI for employees considered in this article. The resulting gross sample contains 520,887 records based on 158,876 individuals (on average 3.3 yearly observations per individual).

In order to assess the effect of financial incentives on the probability of entering the DI scheme, the replacement rates of Dutch Labour Inspectorate are linked to the individuals in our gross sample. An overview of replacement rates of sectors was given in Table 6 , and since no substantial changes in replacement rates have occurred in the period $1996-2002,{ }^{14}$ we have linked

14 We have verified this claim with an alternative dataset called the 'FNV CAO Databank', and indeed found that all replacement rates remained constant over the period concerned. 
TABLE 1 - SAMPLE CHARACTERISTICS IPO, 1996-2000

\begin{tabular}{lllll}
\hline & $\begin{array}{l}\text { Gross sample } \\
\text { In sample } \\
\text { (\% of sample } \\
\text { size) }\end{array}$ & $\begin{array}{l}\text { DI enrolment } \\
\text { (\% of concerning } \\
\text { category) }\end{array}$ & $\begin{array}{l}\text { Net sample } \\
\text { In sample } \\
\text { (\% of sample } \\
\text { size) }\end{array}$ & $\begin{array}{l}\text { DI enrolment } \\
\text { (\% of concerning } \\
\text { category) }\end{array}$ \\
\hline Total & 100.0 & 0.39 & 100.0 & 0.46 \\
Woman & 40.4 & 0.51 & 26.1 & 0.52 \\
Man & 59.6 & 0.31 & 73.9 & 0.44 \\
Age, 29 & 29.0 & 0.19 & 28.6 & 0.16 \\
Age, 30-34 & 13.6 & 0.37 & 13.3 & 0.42 \\
Age, 35-39 & 15.1 & 0.38 & 14.8 & 0.43 \\
Age, 40-44 & 14.1 & 0.45 & 14.1 & 0.56 \\
Age, 45-49 & 12.2 & 0.47 & 12.9 & 0.60 \\
Age, 50-54 & 9.1 & 0.64 & 10.2 & 0.73 \\
Age, 55-59 & 4.5 & 0.89 & 5.0 & 1.12 \\
Age, above 60 & 2.1 & 0.42 & 1.2 & 0.62 \\
Couple & 72.2 & 0.44 & 73.5 & 0.54 \\
Single & 27.8 & 0.27 & 26.5 & 0.23 \\
With children & 55.1 & 0.36 & 53.3 & 0.39 \\
No children & 44.9 & 0.43 & 46.7 & 0.54 \\
Manufacturing sector & 5.5 & 0.35 & 26.9 & 0.38 \\
Construction sector & 5.4 & 0.53 & 26.3 & 0.59 \\
Trade and Food sector & 7.3 & 0.34 & 33.6 & 0.39 \\
Transport and Storage & & & & \\
$\quad$ sector & 2.7 & 0.51 & & \\
Other sector or sector & & & & - \\
$\quad$ unknown & 79.1 & 0.38 & & \\
\hline
\end{tabular}

these figures to the individuals in the IPO dataset for the period 1996-2000. This is possible because we observe the sector an individual works in. The resulting dataset contains 97,950 records from 34,404 individuals (on average 2.8 yearly observations per individual).

In total, 448 of the 97,950 observations enter the DI scheme $(0.46 \%$; see Table 1). This is a little higher than the enrolment rate observed in the gross sample $(0.39 \%)$, but this difference can be attributed to the selection of sectors. It should however be noted that the actual macro figures concerning DI inflow are higher: over the period concerned the average macro DI enrolment figure was $1.2 \%$ [Lisv (various years)]. A possible reason for this is that not all entrants in DI are observed as such. In section 5 we will further address this point.

The sample characteristics of our net sample are well in line with those of the gross sample. Only the proportion between males and females differs in both samples, but this is (again) a straightforward consequence of the selection of particular sectors. It can be read from Table 1 that $26 \%$ of the 
individuals in the dataset consist of women, of which $0.52 \%$ enter the DI scheme during the period 1996-2000. Older individuals show a higher DI enrolment during this period than younger individuals. The household characteristics indicate that couples have a higher DI enrolment than singles, and that households with children have a lower DI enrolment than households without children. The construction sector shows a higher DI enrolment percentage than other sectors.

\section{EMPIRICAL STRATEGY}

As was discussed in section 3, DI program participation results from two contingencies: the probability that a worker claims to be disabled and applies for DI benefits, and the probability that the claim will be awarded by the programme administrator. In most previous research the typical approach was to estimate a single reduced form model of the final allowance decision. The main reason for this is the lack of data needed to identify the parameters which govern the separate stages of the process. Our analysis will be no exception to this line of research. In contrast, a number of studies were able to estimate a multistage model describing the various stages of the application and award decision (e.g. Lahiri et al. (1995), Riphahn and Kreider (1998), BenitezSilva et al. (1999)).

In the previous section it appeared that the observed DI inflow probabilities in the IPO sample are substantially lower than the macro figures published by Lisv (various years). This could be the result of incomplete observation of DI enrolment, since the administrations of the National Tax Office and the DI Administration Office are separate. As appeared from Table 1, this is not so much the result of our sample selection procedure, but rather a (possible) characteristic of the dataset used. In this section we discuss a strategy which is robust to misclassification of the dependent variable, provided that the underlying process is correctly specified by the Logit model. Furthermore, we specify the log-likelihood for our sample subject to the bounded Logit model, and briefly discuss a specification test we will use. The latter is extremely important in this case, as our solution to the incomplete observation problem hinges on the Logit specification.

Define $Y$ as the variable indicating whether DI enrolment takes place $(Y=1)$ or not $(Y=0)$, and suppose that this event can be modelled through the well-known Logit model:

$$
p_{1}=\operatorname{Pr}\{Y=1\}=\frac{\exp \left(x^{\prime} \beta\right)}{1+\exp \left(x^{\prime} \beta\right)},
$$

where the vector $x$ contains a range of explanatory variables. Furthermore, suppose that a fraction of the observations with $Y=0$ is incorrectly observed, 
that is $\pi=\operatorname{Pr}\{Y=0 \mid Z=1\}$ is greater than zero. ${ }^{15}$ Here the observed binary variable is denoted by $Y$, while the true score is denoted by $Z$. In our case, this means that some observations are not coded as DI entrants, while they should be. Now if we assume that $p_{1}$ is Logit then the probability of observing DI enrolment equals

$$
\begin{aligned}
q_{1} & =\operatorname{Pr}\{Y=1\}=1-\operatorname{Pr}\{Y=0 \mid Z=1\} p_{1}-\operatorname{Pr}\{Y=0 \mid Z=0\}\left(1-p_{1}\right) \\
& =p_{1}(1-\pi),
\end{aligned}
$$

so that the probability of observing $Y=1$ equals

$$
q_{1}=(1-\pi) \frac{\exp \left(x^{\prime} \beta\right)}{1+\exp \left(x^{\prime} \beta\right)} .
$$

Note that it is assumed here that $\operatorname{Pr}\{Y=0 \mid Z=0\}=1$,i.e. if no DI enrolment takes place then this is always correctly indicated in our data. This model is identical to the so-called 'bounded Logit model' (see, e.g. Cramer (2004)). Based on this probability we specify the likelihood function as:

$$
\ell(\beta, \pi)=\sum_{i=1}^{n}\left\{y_{i} \ln q_{1}\left(x_{i}, \beta, \pi\right)+\left(1-y_{i}\right) \ln \left(1-q_{1}\left(x_{i}, \beta, \pi\right)\right)\right\},
$$

where individual-year observations are indexed by $i$, the total number of observations in the sample is $n$, and $y_{i}$ indicates DI enrolment for observation $i$. It is assumed that individual heterogeneity can be captured by the variables in $x_{i}$, i.e. we estimate the pooled model. An important argument in favour of pooled estimation is that both the elasticity and the marginal effect of $q_{1}$ with respect to variables in $x$ (in particular DIWR) are less sensitive for the neglect of unobserved heterogeneity than the parameters in $\beta$ themselves. ${ }^{16}$ This was recently confirmed in a Monte Carlo study by Cramer (2005), who hardly finds any bias in the estimated marginal effects. Another recent Monte Carlo study by Greene (2004) finds that the pooled estimator performs better if the number of observations per individual is small, while the fixed effects estimator (full estimation) does relatively better if the number

15 See Hausman et al. (1998) for a more general treatment of the topic.

16 According to Greene (2004) this is particularly the case for continuous covariates. Of course, it should be mentioned that Conditional Logit estimation (CLE) has some theoretical advantages over pooled estimation, but there are two important practical problems with CLE. First, no 'average partial effects' or elasticities can be computed, as the fixed effects distribution remains unknown, and second, the model is only identified from the 'within' dimension of the data, which in our case means that only the individuals entering DI contribute to the likelihood, while others $(99,5 \%$ of our data) are discarded. 
of observations per individual increases. ${ }^{17}$ For our case, this is another argument in favour of the pooled model, as the number of observations per individual is at most 5 (and on average less than 3; see section 4.2).

In the preceding discussion it has become clear that the assumption of the Logit specification is crucial for our analysis. It is therefore necessary to test this assumption. For instance, we can test whether the predicted fraction with $Y=1$ in the sample is consistent with the shape of the bounded Logit curve. Suppose that the observations are ordered into $G$ different groups by their predicted probabilities $q_{1}(i)$ for individual $i$, i.e.:

$$
\max _{i \in I(g-1)} q_{1}(i) \leq \min _{i \in I(g)} q_{1}(i),
$$

for all $g=2, \ldots, G$, and $I(g)$ is the set of individuals in group $g$. Denote with $n_{g}$ the number of observations in group $g$, with $f_{g}$ the fraction of observations in this group with $Y=1$, and with $q_{1}(g)$ the average predicted probability of $Y=1$ for this group. Under the null hypothesis that the observations are in accordance with the (bounded) Logit model, the Hosmer-Lemeshow test statistic

$$
C=\sum_{g=1}^{G} n_{g} \frac{\left(f_{g}-q_{1}(g)\right)^{2}}{r_{1}(g)\left(1-q_{1}(g)\right)}
$$

has a chi-square distribution with G-2 degrees of freedom (Hosmer and Lemeshow $(1980,2000)$ ). When small probabilities are involved, Cramer $(2003,2004)$ advocates the use of groups with equal numbers of observations. The point is that if the composition of the groups is based on percentiles of $q_{1}$, then the sample population will be extremely unevenly distributed across different groups, so that the test loses much of its power. As our case typically involves small probabilities (of DI enrolment) we will apply Cramer's version of the Hosmer-Lemeshow test.

\section{ESTIMATION RESULTS}

Estimation results for two different specifications are shown in Table 2. Panel (1) shows results for the bounded Logit model with the replacement rates in the two first years as explanatory variables, and panel (2) uses the DI Wealth Rate incentive measure discussed in section 4.1. Both specifications include the lagged DI enrolment per sector and dummy variables for each (broadly

17 For this matter, the author has presented results for the Probit model, but these are likely to carry over to the Logit model. Note that the third possibility, random effects estimation, is unattractive, because this involves the rarely satisfied assumption that random effects are uncorrelated with the covariates in $x$. Greene (2004) indeed finds that random effects estimation is inferior to both pooled and fixed effects estimation. 
defined) sector, in an attempt to correct for sector-specific effects. Lagged DI enrolment is determined over the same sectors as the DI Wealth Rate, but it can be identified separately from the latter as it varies more over different sectors. ${ }^{18}$ This variable is likely to be a good first predictor for the individual enrolment probability, and indeed the concerning estimates are close to unity. Furthermore, the significantly positive dummy variable for the Construction sector suggests that, after controlling for individual, household and financial variables, the individual risk of DI enrolment is higher in that sector than in other sectors. This seems plausible, as the work in this sector is in general physically more demanding.

Coefficients on the replacement rates and the DI Wealth Rate show the correct (positive) sign, although the former are surrounded by rather wide confidence intervals. As was apparent in equation (4.1), the DI Wealth Rate nonlinearly depends on the discount factor $\rho$. It turned out to be difficult numerically to find the optimal value for this parameter, so that we have repeatedly estimated both models for fixed values of $\rho$ and finally reported those estimates for which the Likelihood attained its maximum value. The optimal value for $\rho$ was 0.79 , implying an individual discount rate of $21 \%$. This may appear high, but as was noted in section 4.1 DI recipients face several forms of risk with respect to their future DI benefits (e.g. medical reassessments), which justifies an additional 'risk premium'. It is however noted that the estimation results are rather insensitive for (local) variations in $\rho$. In specification (2) the point estimate for the DI Wealth Rate parameter equals 0.72 , which translates into a marginal effect of $3.30 \cdot 10^{-3}$ or an elasticity of DI enrolment with respect to the DI Wealth Rate of 2.5 (see Table 3). In this last table it can also be read that the model specification (2) predicts that a constant replacement rate of $75 \%$ implies a $17 \%$ higher incidence of DI enrolment than a constant replacement rate of $70 \%$. It is expected a priori that the marginal effect with respect to the DI Wealth Rate is comparable to that with respect to the replacement rate in the first year, and indeed this turns out to be the case [see panel (1) in Table 3]. One would however expect that the effect with respect to the replacement rate in the second year is smaller than that in the first year as a result of individual time preference. This is not what our point estimates indicate, but we cannot draw any strong conclusions on the discount rate on the basis of these estimations because of the wideness of confidence intervals. Further simulations show that raising replacement rates in the first and second year by $5 \%$-points leads to an increase in DI enrolment by $6 \%$. Again, both specifications show very similar effects.

Returning to Table 2, the other parameter values mostly show their expected signs. The risk of DI enrolment tends to become higher for higher

18 In fact, the correlation between both variables (over the sample of individuals) amounts no more than 0.11 . 
TABLE 2 - ESTIMATION RESULTS FOR BOUNDED LOGIT MODEL WITH DI ENROLMENT AS ENDOGENOUS VARIABLE, ASYMPTOTIC STANDARD ERRORS BETWEEN PARENTHESES, $n=97,950$

\begin{tabular}{|c|c|c|c|c|}
\hline & (1) & & (2) & \\
\hline Log-Likelihood & -2719.89 & & -2717.99 & \\
\hline Constant & $-7.20 * *$ & $(0.68)$ & $-8.90 * *$ & (1.18) \\
\hline \multicolumn{5}{|l|}{ Financial variables } \\
\hline DI Wealth Rate & - & & $0.72 * *$ & $(0.31)$ \\
\hline Replacement rate year 1 & 0.61 & $(0.49)$ & - & \\
\hline Replacement rate year 2 & 0.67 & $(0.77)$ & - & \\
\hline Lagged Income & $-0.09 * *$ & $(0.03)$ & $-0.09 * *$ & $(0.03)$ \\
\hline Lagged DI enrolment in sector ${ }^{\mathrm{a}}$ & $1.15 * *$ & $(0.21)$ & $1.11 * *$ & $(0.20)$ \\
\hline \multicolumn{5}{|l|}{ Age category ${ }^{b}$} \\
\hline $30-34$ & $1.23 * *$ & $(0.26)$ & $1.23 * *$ & $(0.25)$ \\
\hline $35-39$ & $1.29 * *$ & $(0.27)$ & $1.30 * *$ & $(0.26)$ \\
\hline $40-44$ & $1.39 * *$ & $(0.26)$ & $1.41 * *$ & $(0.25)$ \\
\hline $45-49$ & $1.30 * *$ & $(0.26)$ & $1.34 * *$ & $(0.25)$ \\
\hline $50-54$ & $1.49 * *$ & $(0.26)$ & $1.61 * *$ & $(0.26)$ \\
\hline $55-59$ & $1.94 * *$ & $(0.28)$ & $2.30 * *$ & $(0.31)$ \\
\hline $60-64$ & $1.38 * *$ & $(0.49)$ & $2.51 * *$ & $(0.63)$ \\
\hline \multicolumn{5}{|l|}{ Household situation ${ }^{\mathrm{b}}$} \\
\hline Female/single & -0.53 & $(0.39)$ & -0.52 & $(0.38)$ \\
\hline Female/with partner & $0.40 *$ & $(0.24)$ & $0.41 *$ & $(0.23)$ \\
\hline Male/with partner & 0.16 & $(0.22)$ & 0.16 & $(0.22)$ \\
\hline \multicolumn{5}{|l|}{ Children in household ${ }^{\mathrm{b}}$} \\
\hline Younger than 6 years & $-0.74 * *$ & $(0.20)$ & $-0.75 * *$ & $(0.20)$ \\
\hline $6-12$ years & $-0.37 * *$ & $(0.19)$ & $-0.37 * *$ & $(0.18)$ \\
\hline 12 years or older & -0.14 & $(0.16)$ & -0.14 & $(0.16)$ \\
\hline \multicolumn{5}{|l|}{ Sector ${ }^{b}$} \\
\hline Manufacturing & -0.21 & $(0.19)$ & -0.10 & $(0.18)$ \\
\hline Construction & $0.42 * *$ & $(0.18)$ & $0.54 * *$ & $(0.19)$ \\
\hline Trade and food & -0.08 & $(0.19)$ & 0.04 & $(0.18)$ \\
\hline \multicolumn{5}{|l|}{ Year ${ }^{b}$} \\
\hline 1997 & $-0.31 * *$ & $(0.16)$ & $-0.31 * *$ & $(0.15)$ \\
\hline 1998 & $-0.34 * *$ & $(0.16)$ & $-0.34 * *$ & $(0.15)$ \\
\hline 1999 & $-0.72 * *$ & $(0.18)$ & $-0.72 * *$ & $(0.17)$ \\
\hline 2000 & $-0.59 * *$ & $(0.17)$ & $-0.59 * *$ & $(0.16)$ \\
\hline Bound & $0.76 * *$ & $(0.07)$ & $0.82 * *$ & $(0.09)$ \\
\hline Discount rate & - & & 0.21 & - \\
\hline
\end{tabular}

* Significantly different from zero at $10 \%$ confidence level (asymptotic $t$-test).

** Significantly different from zero at $5 \%$ confidence level (asymptotic $t$-test). For the variable 'Bound' the relevant hypothesis is whether it is equal to one. As can be seen, the asymptotic $t$-test rejects this hypothesis in both model specifications.

a This variable is defined as the average DI enrolment over the period 1993-1995 for the sector the individual is working in, and is computed on the basis of our sample.

b The reference categories for these dummy variables are: 'younger than 30 years of age', 'male/single', 'no children', 'Transport and Storage' and '1996', respectively. 
TABLE 3 - IMPLIED EFFECTS OF FINANCIAL INCENTIVES

Marginal effects ${ }^{\mathrm{a}}$

w.r.t. DI wealth rate

w.r.t. replacement rate year 1

w.r.t. replacement rate year 2

Implied elasticities ${ }^{\mathrm{a}}$

w.r.t. DI wealth rate

w.r.t. replacement rate year 1

w.r.t. replacement rate year 2

Implied effect on DI enrolment in \%-points

$\mathrm{RR}_{1}$ and $\mathrm{RR}_{2}$ are raised from 70 to $75 \%\left(\mathrm{RR}_{3}=70 \%\right)$

$R_{1}$ and $R_{2}$ are raised from 70 to $90 \%\left(R_{3}=70 \%\right)$

$R_{1}, R_{2}$ and $R_{3}$ are raised from 70 to $75 \%$

$\mathrm{RR}_{1}, \mathrm{RR}_{2}$ and $\mathrm{RR}_{3}$ are raised from 70 to $90 \%$
(1)

$\begin{array}{lll}- & & 0.0033 \\ 0.0028 & (0.0022) & - \\ 0.0031 & (0.0035) & - \\ & & \\ - & & 2.50 * * \\ 0.53 & (0.43) & - \\ 0.50 & (0.58) & -\end{array}$

(2)

$0.03 \quad(=6 \%) \quad 0.03 \quad(=6 \%)$

$0.12 \quad(=25 \%) \quad 0.12 \quad(=26 \%)$

- $0.08 \quad(=17 \%)$

- $\quad 0.32 \quad(=69 \%)$

a Asymptotic standard errors have been computed with the Delta method, and are reported between parentheses.

ages. Note however that in specification (1) the coefficient for the age category 60-64 is smaller than that for ages 50-59, while in specification (2) we observe a monotonic age pattern. A probable reason is that the second specification takes the relatively short time horizon faced by the elderly into account, compare equation (4.1). For women, it is seen that living together with a partner increases the risk of DI enrolment, while for men there does not appear to be a strong effect. On the other hand, having young children appears to have a negative impact on the propensity to DI enrolment. There is no obvious explanation for this. Perhaps parents have a larger incentive to earn sufficient income in order to satisfy the needs of their children.

As was discussed in section 5, the Hosmer-Lemeshow test is in fact a specification test for the (bounded) Logit model, so that this test gives us some indication whether our empirical strategy discussed in section 5 is valid. Results of the Hosmer-Lemeshow test for specification (2) are shown in Table 4 and Figure 2, with group sizes equalling 9,794 or 9,795 (i.e. each group contains $10 \%$ of our sample). The resulting test statistic equals 10.9 , which is lower than the $5 \%$ critical value in the chi-square distribution of 15.5. Thus, the bounded Logit model cannot be rejected. The last two columns in Table 4, and Figure 2, indeed show that the 'curvature' of the predicted probabilities does not deviate too much from the postulated curvature of the bounded Logit model. Note that on the basis of this statistical test the alternative model specification (1) can also not be rejected, with a test statistic equalling 12.6.

In Table 5 estimation results for some interesting parameters in alternative specifications are reported. Specification (3) includes interaction effects 
TABLE 4 - HOSMER-LEMESHOW TEST (WITH EQUAL GROUP SIZES) OF THE BOUNDED LOGIT MODEL

\begin{tabular}{lllll}
\hline $\begin{array}{l}\text { Number of } \\
\text { observations } \\
\text { in interval }\end{array}$ & $\begin{array}{l}\text { Lower bound } \\
(\%)\end{array}$ & $\begin{array}{l}\text { Upper bound } \\
(\%)\end{array}$ & $\begin{array}{l}\text { Observed } \\
\text { fraction of DI } \\
\text { enrolment (\%) }\end{array}$ & $\begin{array}{l}\text { Average } \\
\text { predicted } \\
\text { probability of } \\
\text { DI enrolment } \\
(\%)\end{array}$ \\
\hline 9794 & 0.00 & 0.10 & 0.09 & 0.07 \\
9795 & 0.10 & 0.15 & 0.09 & 0.12 \\
9795 & 0.15 & 0.21 & 0.13 & 0.18 \\
9795 & 0.21 & 0.27 & 0.27 & 0.24 \\
9795 & 0.27 & 0.34 & 0.38 & 0.30 \\
9795 & 0.34 & 0.43 & 0.33 & 0.39 \\
9795 & 0.43 & 0.55 & 0.40 & 0.49 \\
9795 & 0.55 & 0.70 & 0.59 & 0.62 \\
9795 & 0.70 & 0.95 & 0.97 & 0.81 \\
9795 & 0.95 & 6.61 & 1.33 & 1.37 \\
\hline
\end{tabular}

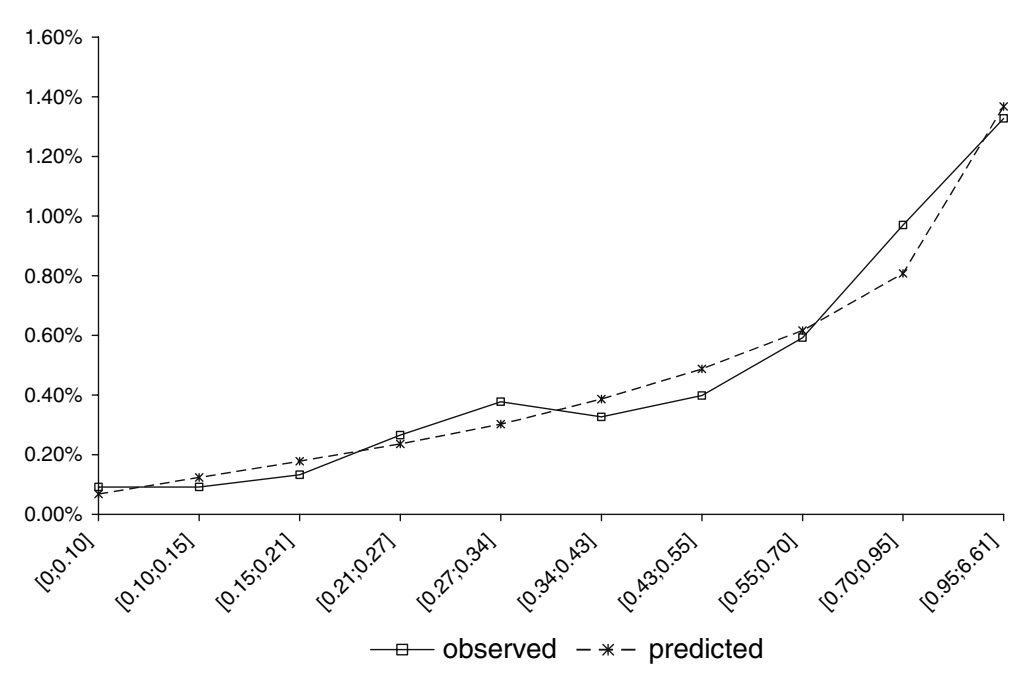

Figure 2 - Fit of the predicted probabilities for ten equally sized groups in the bounded Logit model

between age and time in order to investigate whether there is a shift in the age pattern over time. As was discussed in section 2, some policy measures taken during early 1990s were aimed at reducing the inflow into DI. While these effects may for an important part be captured by the year dummy variables, it is well possible that effects differ between different age groups. It can however be read from the estimated coefficients and standard errors that 
there is no evidence for this. A test of the null hypothesis that coefficients for those aged 50 in years 1998, 1999 or 2000 are jointly equal to zero cannot be rejected (the concerning $F$-statistic equals 0.35 , with a critical value of 2.60 at the $5 \%$ confidence level), i.e. there is no proof that the risk of DI enrolment has decreased for the elderly during these 3 years. As specification (2) is nested in specification (3) we can also perform a likelihood ratio test. The resulting chi-square statistic with four degrees of freedom equals 6.2 , so that we cannot reject the restricted version of the model at any conventional significance level. The pattern of the year effects in all specifications (1)-(5) nonetheless suggests that the general risk on DI enrolment has structurally decreased over the years, which may be the result of policy measures taken during early 1990s. Note that the parameter estimates not reported in Table 5 remain qualitatively the same as those in specifications (1) and (2) (see Table 2).

Specification (4) in Table 5 includes the replacement rate in the third year as an explanatory variable. Compared to specification (1) without this variable, it becomes clear that the likelihood is hardly increased. The point estimate for the coefficient $\mathrm{RR}_{3}$ is large, which is in accordance with equation (4.1). This estimate is however based on very limited variation in this variable (see Table 6), which results in a high-standard error. An interesting point is that the likelihood in specification (4) remains lower than that with DIWR as an explanatory variable, while the latter preserves more degrees of freedom. Apparently, the model fit is greatly improved by including an interaction term $\rho^{63-\mathrm{AGE}} \cdot \mathrm{RR}_{3}-$ even if the parameters are constrained beforehand. ${ }^{19}$ Thus, taking into account that the elderly face a shorter time horizon than younger individuals improves the model. Also, it is noted (again) that the pattern of age dummy variables is monotonic in the specifications with DIWR, while in other specifications it is not. In conclusion, we observe that (i) specifications (3) and (4) do not (statistically) improve upon specifications (2) and (1), respectively, and that (ii) the specification with DIWR as an explanatory variable has a higher likelihood than other specifications while preserving more degrees of freedom. ${ }^{20}$ From these comparisons we may conclude that the model specification (2) is to be preferred over specifications (1), (3) and (4).

Finally, in order to check the robustness of our findings, we estimate a specification where replacement rates of the first and second year are clustered in categories ranging from 70 to $80 \%$ (base case), 80 to $90 \%$ and 90 to $100 \%$ (specification (5) in Table 5). It can be seen that all coefficients show the correct sign, and that some estimates are significantly different from zero at a $10 \%$ confidence level. The implied effects are somewhat lower than those

19 Note that $\beta$ DIWR $=\beta \mathrm{RR}_{1}+\gamma_{1} \mathrm{RR}_{2}+\gamma_{2} \mathrm{RR}_{3}+\gamma_{3} \rho^{63-\mathrm{AGE}} \mathrm{RR}_{3}$, where all $\gamma_{i}$ are (constrained to be) functions of $\beta$ and $\rho$ (compare equation (4.1)).

20 It is however not possible to perform a formal (Likelihood Ratio) test here, as specification

(2) is not nested in the other specifications (or vice versa). 
TABLE 5 - ESTIMATION RESULTS FOR SOME ALTERNATIVE SPECIFICATIONS, ASYMPTOTIC STANDARD ERRORS BETWEEN PARENTHESES, $n=97950$

\begin{tabular}{|c|c|c|c|c|c|c|}
\hline & (3) & & (4) & & (5) & \\
\hline Log-Likelihood & -2714.89 & & -2719.56 & & -2716.10 & \\
\hline \multicolumn{7}{|l|}{ Financial variables } \\
\hline DI Wealth Rate & $0.71 * *$ & $(0.32)$ & - & & - & \\
\hline Replacement rate year 1 & - & & 0.67 & $(0.56)$ & - & \\
\hline Replacement rate year 2 & - & & 0.64 & $(0.86)$ & - & \\
\hline Replacement rate year 3 & - & & 2.12 & $(3.44)$ & - & \\
\hline $\mathrm{RR}_{1}$ between 90 and $100 \%$ & - & & - & & 0.22 & $(0.17)$ \\
\hline $\mathrm{RR}_{1}$ between 80 and $90 \%$ & - & & - & & $0.45 *$ & $(0.24)$ \\
\hline $\mathrm{RR}_{2}$ between 90 and $100 \%$ & - & & - & & $0.40 *$ & $(0.21)$ \\
\hline $\mathrm{RR}_{2}$ between 80 and $90 \%$ & - & & - & & 0.15 & $(0.15)$ \\
\hline \multicolumn{7}{|l|}{ Age category } \\
\hline $30-34$ & $1.23 * *$ & $(0.26)$ & $1.23 * *$ & $(0.29)$ & $1.23 * *$ & $(0.28)$ \\
\hline $35-39$ & $1.30 * *$ & $(0.26)$ & $1.30 * *$ & $(0.30)$ & $1.30 * *$ & $(0.28)$ \\
\hline $40-44$ & $1.41 * *$ & $(0.26)$ & $1.39 * *$ & $(0.29)$ & $1.39 * *$ & $(0.27)$ \\
\hline $45-49$ & $1.34 * *$ & $(0.26)$ & $1.30 * *$ & $(0.29)$ & $1.30 * *$ & $(0.27)$ \\
\hline $50-54$ & $1.62 * *$ & $(0.33)$ & $1.50 * *$ & $(0.29)$ & $1.51 * *$ & $(0.28)$ \\
\hline $55-59$ & $2.30 * *$ & $(0.37)$ & $1.95 * *$ & $(0.31)$ & $1.95 * *$ & $(0.29)$ \\
\hline $60-64$ & $2.51 * *$ & $(0.68)$ & $1.39 * *$ & $(0.55)$ & $1.39 * *$ & $(0.51)$ \\
\hline \multicolumn{7}{|l|}{ Year } \\
\hline 1997 & $-0.45 * *$ & $(0.20)$ & $-0.31 *$ & $(0.18)$ & $-0.31 *$ & $(0.17)$ \\
\hline 1998 & $-0.31 *$ & $(0.19)$ & $-0.35 *$ & $(0.18)$ & $-0.34 * *$ & $(0.17)$ \\
\hline 1999 & $-0.61 * *$ & $(0.21)$ & $-0.73 * *$ & $(0.20)$ & $-0.73 * *$ & $(0.19)$ \\
\hline 2000 & $-0.56 * *$ & $(0.20)$ & $-0.60 * *$ & $(0.19)$ & $-0.60 * *$ & $(0.17)$ \\
\hline \multicolumn{7}{|l|}{ Interaction terms } \\
\hline Aged over 50 in 1997 & 0.43 & $(0.34)$ & - & & - & \\
\hline Aged over 50 in 1998 & -0.11 & $(0.35)$ & - & & - & \\
\hline Aged over 50 in 1999 & -0.42 & $(0.41)$ & - & & - & \\
\hline Aged over 50 in 2000 & -0.10 & $(0.36)$ & - & & - & \\
\hline Bound & $0.77 * *$ & $(0.08)$ & $0.61 * *$ & $(0.05)$ & $0.70 * *$ & $(0.06)$ \\
\hline Discount rate & 0.21 & - & - & & - & \\
\hline
\end{tabular}

* Significantly different from zero at $10 \%$ confidence level (asymptotic $t$-test).

** Significantly different from zero at $5 \%$ confidence level (asymptotic $t$-test). For the variable 'Bound' the relevant hypothesis is whether it is equal to one. As can be seen, the asymptotic t-test rejects this hypothesis in both model specifications.

a Note that not all estimated coefficients are reported in the table. Full results are available upon request.

reported in Table 3: an increase in the replacement rate in the first and second year with $20 \%$-points (10\%-points) leads to an increase of DI enrolment with $0.07 \%$-points $(0.03 \%$-points). This is about one third lower than the estimated effects from specifications (1) and (2) reported in Table 3. Finally, we have also estimated a Logit version of the model with DIWR as an explanatory variable (i.e. fixed the bound parameter at unity), and experimented with 
different discount rates. In these estimations the elasticities with respect to the DI Wealth Rate appeared quite robust, sometimes implying somewhat higher elasticity estimates, but lower likelihoods. ${ }^{21}$

\section{CONCLUSION AND DIRECTIONS FOR FURTHER RESEARCH}

In this article, we have estimated the impact of the financial conditions in DI on the individual's probability of DI enrolment. We have found that individuals with relatively high DI Wealth (that is, the ratio of foreseen DI benefits to current income) are more likely to enrol. Based on variation in DI replacement rates between different sectors, we estimate that a 5\%-point increase in the replacement rates in the first and second year of disability raises DI enrolment by $6 \%$, while a general $5 \%$-point increase in the replacement rate increases DI enrolment by $17 \%$. It is however noted that the latter estimate is surrounded by more uncertainty, as the effect of the replacement rate from the third year could not be estimated with high precision. The elasticity of DI enrolment with respect to the DI Wealth Rate was estimated at a value of 2.5. In estimating these figures, we have controlled for individual and household specific characteristics, and have tried to correct for sector specific effects (other than financial conditions) and the possibility of incomplete observation of DI enrolment.

Recently, the Dutch government has decided to reform DI largely along the lines proposed by the Social and Economic Council of The Netherlands (2002). This reform entails, amongst others, an increase of the DI replacement rate with 5\%-points and the abolishment of experience rating in DI employer premiums. $^{22}$ Both these measures are expected to lead to an increase in the DI enrolment rate. It appears from our analysis that a general 5\%-point increase in the replacement rate increases DI enrolment by $17 \%$, while Koning (2004) has shown that the existing experience rating system has reduced DI inflow by about the same percentage. Of course, these figures cannot be added up right away because of overlap, but it is clear that the effect of this part of the proposal may be substantial and possibly harm the government's objective to reduce moral hazard in the Dutch DI scheme. It is however worth of mention that the newly devised DI schedule involves multiple features to combat moral hazard (e.g. stricter eligibility criteria) which in turn may result in other adverse financial incentive effects than would be the case in the 'old' DI scheme. It is well possible that adverse incentive effects under the new scheme will be of lower magnitude than the figures just mentioned.

21 Results are available in van Vuren and van Vuuren (2005).

22 Although both these changes are conditional on DI enrolment and the level of supplementary benefits in sickness insurance, it is believed that the likelihood that they will actually take place is large. 
A possible complication with the current empirical analysis is that DI replacement rates may in the long run depend on the risk of DI enrolment. That is, labour unions have a stronger incentive to negotiate high-replacement rates if the risk of DI enrolment is higher. If this is really the case, then the effects reported in this study may overestimate the true effect. Taking account of such a mechanism will however prove difficult, as no appropriate instruments appear to be available. ${ }^{23} \mathrm{~A}$ second point which is left for future research is that the current elasticity has been estimated at given eligibility criteria. As was just mentioned above, it is however likely that the elasticity depends (negatively) on eligibility strictness, so that the evaluation of policy measures including a modification in eligibility criteria would require more precise knowledge of this interdependence.

APPENDIX A. REPLACEMENT RATES PER SECTOR

TABLE 6 - OVERVIEW OF REPLACEMENT RATES OF SECTOR COLLECTIVE LABOUR AGREEMENTS, 2002

\begin{tabular}{lllllll}
\hline $\begin{array}{l}\text { Sector } \\
\text { Code }^{\mathrm{a}}\end{array}$ & Category & Name & $\mathrm{RR}_{1}$ & $\mathrm{RR}_{2}$ & $\mathrm{RR}_{3}$ & $\mathrm{DIWR}^{c}$ \\
\hline 158 & 1 & & & & & \\
\hline 170 & 1 & $\begin{array}{l}\text { Manufacture of bread, fresh } \\
\text { pastry goods and cakes } \\
\text { Manufacture of textiles }\end{array}$ & 85 & 85 & 70 & 692 \\
182 & 1 & $\begin{array}{l}\text { Manufacture of wearing } \\
\text { apparel and accessories (excl. } \\
\text { leather) }\end{array}$ & 100 & 70 & 70 & 693 \\
203 & 1 & $\begin{array}{l}\text { Manufacture of builders } \\
\text { carpentry and joinery }\end{array}$ & 80 & 75 & 75 & 716 \\
212 & 1 & $\begin{array}{l}\text { Manufacture of articles of } \\
\text { paper and paperboard } \\
\text { Printing and service activities } \\
\text { related to printing }\end{array}$ & 100 & 100 & 70 & 720 \\
\hline & 1 & & 100 & 70 & 720 \\
\hline
\end{tabular}

23 That is, variables influencing the replacement rate, but not DI enrolment. A possibility is to estimate a simultaneous model for DI enrolment and the DI replacement rates, but this would require data over a longer time period. The problem with such a long time period is data inconsistency; e.g. the definitions of sectors have changed (in 1993), and the composition of sectors has also changed over the years. It should however be noted that replacement rates for the sectors selected in this paper remained constant over time (see section 4), so that 'changes' in replacement rates are with certainty exogenous with respect to DI enrolment during the period of our study. 
FINANCIAL INCENTIVES IN DISABILITY INSURANCE IN THE NETHERLANDS 95

TABLE 6 - CONTINUED

\begin{tabular}{|c|c|c|c|c|c|c|}
\hline $\begin{array}{l}\text { Sector } \\
\text { Code }^{\text {a }}\end{array}$ & Category $^{\mathrm{b}}$ & Name & $\mathrm{RR}_{1}$ & $\mathrm{RR}_{2}$ & $\mathrm{RR}_{3}$ & $\operatorname{DIWR}^{c}$ \\
\hline 266 & 1 & $\begin{array}{l}\text { Manufacture of articles of } \\
\text { concrete, plaster or cement }\end{array}$ & 100 & 70 & 70 & 693 \\
\hline 270 & 1 & $\begin{array}{l}\text { Manufacture of basic metals } \\
\text { (excl. iron, steel, and } \\
\text { ferro-alloys) }\end{array}$ & 94 & 70 & 70 & 687 \\
\hline 271 & 1 & $\begin{array}{l}\text { Manufacture of basic iron and } \\
\text { steel and of ferro-alloys }\end{array}$ & 70 & 70 & 70 & 663 \\
\hline 280 & 1 & $\begin{array}{l}\text { Manufacture of fabricated } \\
\text { metal products, except machin- } \\
\text { ery and equipment }\end{array}$ & 100 & 70 & 70 & 693 \\
\hline 342 & 1 & $\begin{array}{l}\text { Manufacture of bodies (coach- } \\
\text { work) for motor vehicles; } \\
\text { manufacture of trailers and } \\
\text { semi-trailers }\end{array}$ & 100 & 70 & 70 & 693 \\
\hline 361 & 1 & Manufacture of furniture & 80 & 70 & 70 & 673 \\
\hline 400 & 1 & $\begin{array}{l}\text { Electricity, gas, steam and hot } \\
\text { water supply }\end{array}$ & 90 & 70 & 70 & 683 \\
\hline 452 & 2 & $\begin{array}{l}\text { Building of complete construc- } \\
\text { tions or parts thereof; civil } \\
\text { engineering }\end{array}$ & 70 & 70 & 70 & 663 \\
\hline 453 & 2 & Building installation & 100 & 70 & 70 & 693 \\
\hline 454 & 2 & Building completion & 70 & 70 & 70 & 663 \\
\hline 501 & 3 & Sale of motor vehicles & 100 & 70 & 70 & 693 \\
\hline 513 & 3 & $\begin{array}{l}\text { Wholesale of food, beverages } \\
\text { and tobacco (excl. meat and } \\
\text { meat products) }\end{array}$ & 90 & 80 & 70 & 692 \\
\hline 513 & 3 & $\begin{array}{l}\text { Wholesale of meat and meat } \\
\text { products }\end{array}$ & 100 & 70 & 70 & 693 \\
\hline 514 & 3 & Wholesale of textiles & 100 & 70 & 70 & 693 \\
\hline 514 & 3 & $\begin{array}{l}\text { Wholesale of electrical house- } \\
\text { hold appliances and radio and } \\
\text { television goods }\end{array}$ & 100 & 70 & 70 & 693 \\
\hline 521 & 3 & $\begin{array}{l}\text { Retail sale in non-specialised } \\
\text { stores (excl. stores with food, } \\
\text { beverages or tobacco predom- } \\
\text { inating) }\end{array}$ & 90 & 80 & 70 & 692 \\
\hline 522 & 3 & $\begin{array}{l}\text { Retail sale of meat and meat } \\
\text { products }\end{array}$ & 90 & 70 & 70 & 683 \\
\hline 523 & 3 & Dispensing chemists & 81.25 & 70 & 70 & 675 \\
\hline 523 & 3 & $\begin{array}{l}\text { Retail sale of medical and } \\
\text { orthopaedic goods }\end{array}$ & 90 & 80 & 70 & 692 \\
\hline 524 & 3 & $\begin{array}{l}\text { Retail sale of hardware, paints, } \\
\text { glass, books, newspapers and } \\
\text { stationery }\end{array}$ & 70 & 70 & 70 & 663 \\
\hline 524 & 3 & $\begin{array}{l}\text { Retail sale of household appli- } \\
\text { ances and radio and television } \\
\text { goods }\end{array}$ & 70 & 70 & 70 & 663 \\
\hline
\end{tabular}


TABLE 6 - CONTINUED

\begin{tabular}{|c|c|c|c|c|c|c|}
\hline $\begin{array}{l}\text { Sector } \\
\text { Code }^{\text {a }}\end{array}$ & Category $^{\mathrm{b}}$ & Name & $\mathrm{RR}_{1}$ & $\mathrm{RR}_{2}$ & $\mathrm{RR}_{3}$ & $\operatorname{DIWR}^{c}$ \\
\hline 524 & 3 & Retail sale of clothing & 70 & 70 & 70 & 663 \\
\hline 524 & 3 & $\begin{array}{l}\text { Retail sale of footwear and } \\
\text { leather goods }\end{array}$ & 70 & 70 & 70 & 663 \\
\hline 524 & 3 & Retail sale of textiles & 90 & 70 & 70 & 683 \\
\hline 524 & 3 & $\begin{array}{l}\text { Retail sale of furniture, lighting } \\
\text { equipment and household arti- } \\
\text { cles }\end{array}$ & 80 & 75 & 70 & 678 \\
\hline 550 & 3 & Hotels and restaurants & 100 & 90 & 70 & 711 \\
\hline 552 & 3 & $\begin{array}{l}\text { Camping sites and other provi- } \\
\text { sion of short-stay accommoda- } \\
\text { tion }\end{array}$ & 100 & 90 & 70 & 711 \\
\hline 555 & 3 & Canteens and catering & 100 & 90 & 70 & 711 \\
\hline 601 & 4 & Transport via railways & 90 & 80 & 70 & 692 \\
\hline 602 & 4 & Freight transport by road & 80 & 80 & 80 & 758 \\
\hline 602 & 4 & $\begin{array}{l}\text { Scheduled passenger land trans- } \\
\text { port (excl. railways) }\end{array}$ & 95 & 85 & 70 & 702 \\
\hline 602 & 4 & Taxi operation & 80 & 70 & 70 & 673 \\
\hline \multirow[t]{3}{*}{640} & 4 & Post and courier activities & 85 & 70 & 70 & 678 \\
\hline & & Sample mean & 89 & 75 & 70 & 690 \\
\hline & & Standard deviation & 11 & 8.7 & 1.8 & 20 \\
\hline
\end{tabular}

Source: Labour Inspectorate, own calculations.

a Sector codes are according to the so-called 'SBI 1993' definition. Note, that we have only reported the 3-digit codes here, while some sectors are actually defined on the basis of 4-digit codes.

b Sectors are divided into the following categories: 1 = Manufacturing, $2=$ Construction, $3=$ Trade and food, $4=$ Transport and storage.

c The DI wealth rate (as a percentage of current income) reported in this column is calculated at a discount rate of 10 percent $(\rho=0.9)$ and for the average age in our sample (37 years). Replacement rates for year $\mathrm{t}$ are denoted by $\mathrm{RR}_{t}$. The replacement rate for the third year remains constant for later years, i.e.: $\mathrm{RR}_{3}=\mathrm{RR}_{4}=\mathrm{RR}_{5}=\ldots$

\section{ACKNOWLEDGEMENTS}

The authors thank Rob Euwals, Wolter Hassink, Bas van der Klaauw, Pierre Koning, Peter Kooiman, Maarten Lindeboom, Jan Nelissen, Rocus van Opstal, Hans Roodenburg, Jan-Maarten van Sonsbeek, Frans Suijker, and three anonymous referees for useful comments and discussions; and The Netherlands' Labour Inspectorate, Statistics Netherlands (CBS), and the Amsterdam Institute for Advanced Labour Studies (Aias) for providing data. 


\section{REFERENCES}

Aarts, L. and P. de Jong (1992), Economics Aspects of Disability Behaviour, Amsterdam, North Holland.

Autor, D. and M. Duggan (2002), 'The Rise in Disability Recipiency and the Decline in Unemployment,' MIT Dept. of Economics Working Paper No. 01-15, MIT, Cambridge.

Barr, N. (1993), The Economics of the Welfare State, London, Weidenfeld and Nicholson.

Benitez-Silva, H., M. Buchinsky, H. Chan, J. Rust, and S. Sheidvasser (1999), 'An Empirical Analysis of the Social Security Disability Application, Appeal, and Award Process,' Labour Economics, 6, pp. 147-178.

Black, D., K. Daniel, and S. Sanders (2002), 'The Impact of Economic Conditions on Participation in Disability Programs: Evidence from the Coal Boom and Bust,' American Economic Review, 92, pp. 27-50.

Bosch, van den, F. and C. Petersen (1983), 'An Explanation of the Growth of Social Security Disability Transfers,' De Economist, 131, pp. 65-79.

Bound, L. and R. Burkhauser (1999), 'Economic Analysis of Transfer Programs Targeted on People with Disabilities,' in: O. Ashenfelter and D. Card (eds.), Handbook of Labor Economics, Vol. 3C, Amsterdam, North Holland, pp. 3417-3528.

Cramer, J. (2003), Logit Models from Economics and Other Fields, Cambridge, Cambridge University Press.

Cramer, J. (2004), 'Scoring Bank Loans that May Go Wrong: a Case Study,' Statistica Neerlandica, 58, pp. 365-380.

Cramer, J. (2005), 'Omitted Variables and Misspecified Disturbances in the Logit Model,' TI Discussion Paper 2005-084/4. Tinbergen Institute, Rotterdam/Amsterdam.

Greene, W. (2004), 'The Behavior of the Maximum Likelihood Estimator of Limited Dependent Variable Models in the Presence of Fixed Effects,' Econometrics Journal, 7, pp. 98-119.

Gruber, J. (2000), 'Disability Insurance Benefits and Labour Supply,' Journal of Political Economy, 108, pp. 1162-1183.

Hassink, W. (1996), Worker flows and the employment adjustment of firms, Ph.D thesis, Vrije Universiteit Amsterdam, Tinbergen Institute, Amsterdam/Rotterdam.

Hassink, W. (2000), 'Job Destruction through Quits or Layoffs?', Applied Economics Letters, 7, pp. 45-47.

Hassink, W., J. van Ours, and G. Ridder (1997), 'Dismissal through Disability', De Economist, 145 , pp. 29-46.

Hausman, J., J. Abrevaya, and F. Scott-Morton (1998), 'Misclassification of the Dependent Variable in a Discrete-response Setting,' Journal of Econometrics, 87, pp. 239-269.

Hosmer, D. and S. Lemeshow (1980), 'Goodness of Fit Tests for the Multiple Logistic Regression Model,' Communications in Statistics, A10, pp. 1043-1069.

Hosmer, D. and S. Lemeshow (2000), Applied Logistic Regression, 2nd editionm, New York, Wiley.

Kapteyn, A. and K. de Vos (1999), 'Social Security and Retirement in The Netherlands,' in: J. Gruber and D. Wise (eds.), Social Security and Retirement around the World, Chicago, University Press, pp. 269-304.

Kerkhofs, M., M. Lindeboom, and J. Theeuwes (1999), 'Retirement, Financial Incentives and Health,' Labour Economics, 6, pp. 203-227.

Koning, P. (2004), 'Estimating the impact of experience rating on the inflow into Disability Insurance in The Netherlands,' CPB Discussion Paper 37. CPB Netherlands Bureau for Economic Policy Analysis, The Hague.

Lahiri, K., D. Vaughan, and B. Wixon (1995), 'Modeling SSA's Sequential Disability Determination Process using Matched SIPP Data,' Social Security Bulletin, 58, pp. 3-42. 
Lindeboom, M. (1998), 'Microeconometric analysis of the retirement decision: The Netherlands,' OECD Working Paper 20. OECD, Paris.

Lisv (various years), Ontwikkeling arbeidsongeschiktheid, jaaroverzichten 1996, 1997, 1998, 1999 en 2000, Amsterdam, Landelijk instituut sociale verzekeringen.

OECD (2003), Transforming Disability into Ability; Policies to Promote Work and Income Security for Disabled People, Paris, OECD.

Riphahn, R. and B. Kreider (1998), 'Applications to the U.S. Disability System: A Semiparametric Approach for Men and Women,' IZA Discussion Paper, 17. IZA, Bonn.

Roodenburg, H. and W. Wong Meeuw Hing (1985), 'De arbeidsmarktcomponent in de WAO', CPB Occasional Paper, 34. CPB Netherlands Bureau for Economic Policy Analysis, The Hague.

Social and Economic Council of The Netherlands (2002), Werken aan arbeidsgeschiktheid, SER rapport 5, The Hague, SER.

van Vuren, A. and D. van Vuuren (2005), 'Financial incentives in Disability Insurance in The Netherlands', CPB Discussion Paper, 45. CPB Netherlands Bureau for Economic Policy Analysis, The Hague.

Westerhout, E. (1996), 'Hidden unemployment in Dutch disability schemes,' CPB Report, 1996/2, 24-29.

Woittiez, I., M. Lindeboom, and J. Theeuwes (1994), 'Labour Force Exit Routes of the Dutch Elderly: A Discrete Choice Model,' in: A. Bovenberg (ed.), The Economics of Pensions: The Case of The Netherlands, Rotterdam, Ocfeb, pp. 1-23. 